\title{
Unit of Angle Measurement
}

National Cancer Institute

\section{Source}

National Cancer Institute. Unit of Angle Measurement. NCI Thesaurus. Code C48455.

A unit of measurement of a plane or solid angle. 